\title{
Desenvolvimento e validação de um instrumento para avaliação de iniciativas ambientais em universidades
}

\section{Carine Castro dos Santos ${ }^{1}$ e Guilherme Lerch Lunardi ${ }^{2}$}

\author{
${ }^{1}$ Universidade Federal do Rio Grande, Universidade Federal do Rio Grande. Av. \\ Itália, km 8. Carreiros. Rio Grande-RS, Brasil (CEP 96203-900). \\ ${ }^{2}$ Universidade Federal do Rio Grande. Instituto de Ciências Econômicas, \\ Administrativas e Contábeis. Av. Itália, km 8. Vila Maria. Rio Grande-RS, Brasil (CEP \\ 96203-900). E-mail: gllunardi@furg.br.
}

Resumo. O desenvolvimento econômico e, consequentemente, o aumento da degradação dos recursos naturais tem sido palco de ampla discussão nos últimos anos. A preocupação quanto aos danos provocados ao meio ambiente tem estimulado estudos relacionados à gestão ambiental, fazendo com que organizações públicas e privadas busquem alternativas para mitigar os seus impactos negativos. As instituições de ensino superior (IES), mais especificamente, por seu papel educacional e prático no caminho da sustentabilidade, estão entre essas organizações. Assim, buscou-se neste artigo desenvolver e validar um instrumento para apoiar as universidades na avaliação das suas iniciativas ambientais, sob a percepção da comunidade universitária. 0 estudo foi realizado em uma instituição pública de ensino superior, localizada no extremo sul do Brasil, e os seus resultados analisados com base em 333 respondentes, sendo eles alunos, docentes e técnicos administrativos. Ao final do estudo, propôs-se um modelo contendo quatro fatores que representam diferentes iniciativas ambientais a serem desenvolvidas pelas universidades, sendo eles a educação ambiental, a orientação ambiental, a política ambiental e as ações ambientais. O modelo permite analisar a percepção da comunidade universitária quanto às iniciativas ambientais realizadas pela IES, além de identificar os fatores que influenciam significativamente a implementação das ações ambientais na universidade.

Palavras-chave: Gestão ambiental; Instituições de Ensino Superior; Sustentabilidade ambiental.

Abstract. Development and validation of an instrument for
assessing environmental initiatives in universities. The
economic development and, consequently, the increase of natural
resources degradation has been increasingly discussed in the last
few years. Concerning related to environment damages has been
motivated several studies in environmental management doing
public and private organizations to search for alternatives to

Recebido $28 / 01 / 2020$

Aceito

$13 / 06 / 2020$

Disponível on line $15 / 06 / 2020$

Publicado

$31 / 08 / 2020$

Acesso aberto

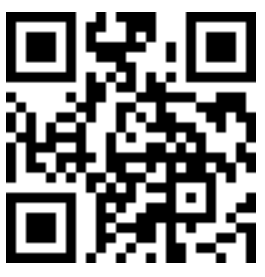

ORCID

(1) 0000-0003-3557-7734

Carine Castro dos Santos

D) 0000-0003-3250-2796 Guilherme Lerch Lunardi 
mitigate its negative impacts. Superior education institutions are among these organizations, specifically because of its educational and practical role in the way of sustainability. Thus, we aimed in this study to develop and validate an instrument to support universities to evaluate their environmental initiatives, based on the university community's perception. The study was conducted in a Federal Public University, located in the extreme south of Brazil, which data was collected from 333 respondents, namely students, professors and administrative technicians. Afterwards, we proposed a conceptual model with four factors representing different environmental initiatives to be developed by the universities, such as environmental education, environmental orientation, environmental politics and environmental actions. The model enhances to analyze the perception of the university community regarding its environmental initiatives and to identify those factors that significantly influence the implementation of the environmental actions developed by the University.

Keywords: Environmental management; Superior Education Institutions; Environmental sustainability.

\section{Introdução}

O crescimento da industrialização, a expansão demográfica, a produção e o consumo descontrolados, somados à urbanização e à modernização agrícola geraram desenvolvimento econômico e, consequentemente, uma maior degradação dos recursos naturais. A questão ambiental, nesse sentido, tem sido tema de muita discussão nos últimos anos, devido à preocupação com a manutenção dos recursos naturais e com os danos provocados pelo homem à Natureza e ao meio ambiente (Druzzian e Santos, 2006; Paradiso et al., 2014).

Essa maior inquietação por parte da sociedade com relação à situação ambiental em que se encontra o nosso planeta, bem como a busca de soluções para minimizar e até mesmo eliminar os impactos negativos proporcionados ao meio ambiente vem estimulando crescentes estudos na área (Campos, 2012; Almeida e Sellitto, 2013; Campos et al., 2015). Em decorrência destes problemas, a gestão ambiental e o desenvolvimento sustentável passaram a ser importantes elementos considerados por gestores públicos e privados, bem como pesquisadores, mesmo que muitas vezes motivados por interesses diversos ou obrigados por força social ou legal (Gazzoni et al., 2018).

No caso das instituições de ensino superior (IES), cada vez mais a questão ambiental vem fazendo parte de seu planejamento estratégico e de suas rotinas diárias, entre as quais se destaca, também, a implementação de sistemas de gestão ambiental SGA (Motta et al., 2017). Segundo os mesmos autores, diversos estudos têm demonstrado uma série de benefícios obtidos pelas IES a partir da adoção de tais sistemas, como: uma melhor regulação das responsabilidades e competências interinstitucionais, a redução nos riscos de penalidades legais e passivos ambientais, a melhoria na relação com os órgãos públicos, especialmente os de fiscalização ambiental; a melhoria da imagem da organização, a redução dos custos operacionais (em especial aqueles associados ao consumo de energia, água, e materiais de expediente), a utilização do sistema de gestão ambiental como ferramenta para implantar práticas de educação ambiental transdisciplinares, e o desenvolvimento de expertise que pode ser traduzida tanto em oportunidades de pesquisa quanto de prestação de serviços. 
Entretanto, segundo Rodrigues et al. (2007), as universidades brasileiras ainda encontram inúmeras dificuldades para incorporar a dimensão ambiental. Assim, um dos principais motivadores para a realização do presente estudo é o fato de que, atualmente, as IES vêm cada vez mais adotando práticas ambientalmente sustentáveis em suas rotinas, seja por motivações legais ou por interesse próprio, sem que saibam o quão efetivas têm sido estas práticas, assim como quais ações institucionais têm favorecido a sua implementação.

Considerando a necessidade de melhor compreender a relação entre as diferentes iniciativas ambientais desempenhadas pelas IES e a sua implementação de forma efetiva propôs-se neste artigo o desenvolvimento e a validação de um instrumento para apoiar os gestores universitários na avaliação das suas iniciativas ambientais, na percepção da comunidade universitária.

Neste sentido, avaliar as diferentes ações institucionais ambientais implementadas pelas IES e seus resultados, em termos de contribuições para o aumento da sustentabilidade ambiental, torna-se uma importante oportunidade para analisar o que vem sendo feito - na prática - pelas universidades e se estas vêm obtendo resultados de modo a se tornarem instituições mais ambientalmente corretas.

\section{A gestão ambiental e as instituições de ensino superior}

A gestão ambiental compreende as diretrizes e atividades realizadas por uma organização para atingir resultados positivos sobre o meio ambiente, reduzindo, eliminando ou até mesmo compensando os problemas ambientais decorrentes das suas atividades, além de evitar que outros ocorram no futuro (Barbieri, 2016). Segundo o mesmo autor, as primeiras ações de gestão ambiental foram estimuladas pelo esgotamento e escassez de recursos, cuja exploração havia se intensificado desde a era medieval. Esses primeiros atos em defesa da Natureza não eram resultantes de uma preocupação com o meio ambiente, mas sim de um interesse em preservar os recursos, tendo em vista sua utilização.

Em linhas gerais, a gestão ambiental envolve uma série de atividades práticas, responsabilidades, procedimentos e processos, no intuito de mobilizar atividades internas, administrativas e operacionais comuns, baseadas na tentativa de diminuir ou extinguir os danos causados pelas ações humanas. Deste modo, busca promover o equilíbrio entre os aspectos sociais, políticos, econômicos e ambientais, ponderando as partes envolvidas, bem como as normas emanadas do poder público e entidades com concessão para emitir normatizações a respeito (Silva et al., 2018).

Segundo Tauchen e Brandli (2006), a preocupação com o desenvolvimento sustentável e a gestão ambiental vem se tornando um tema recorrente nas universidades. Isto tem se mostrado bastante presente na prática educacional, seja preparando os estudantes, disponibilizando informações e conhecimento sobre gestão ambiental, ou ainda nos exemplos práticos incorporados na operação de seus campi. Nesse contexto, evidencia-se o potencial que as IES têm para diminuir os impactos negativos sociais e ambientais presentes no seu entorno, e ao mesmo tempo instruir e conscientizar os indivíduos no que tange às questões ambientais. Assim, tais instituições podem adotar a gestão ambiental como uma forma de interface com o meio ambiente, além de mostrar a relação da teoria com a prática e seus benefícios na administração do campus (Alves, 2017).

Tauchen e Brandli (2006) destacam que as Instituições de Ensino Superior começaram a incluir a temática ambiental em seus procedimentos de gestão a partir dos anos 1960. As primeiras experiências surgiram nos Estados Unidos, juntamente com a promoção de profissionais nas Ciências Ambientais, que se estenderam ao longo dessa e da década seguinte. Já nos anos 1980, as universidades passaram a priorizar políticas mais 
voltadas ao tratamento de resíduos e à eficiência energética, desenvolvendo, na década seguinte, políticas ambientais de âmbito global, envolvendo diferentes contextos em que estão inseridas as instituições. No Brasil, Nolasco et al. (2006) afirmam que as experiências ligadas aos Sistemas de Gestão Ambiental vêm sendo realizadas nas últimas décadas, porém em casos de iniciativas separadas.

Mais recentemente, tem se acentuado o reconhecimento do papel que as universidades podem desempenhar no apoio à transformação da sociedade em um organismo mais sustentável. Dentre as ações levantadas, destaca-se a possibilidade de institucionalização da sustentabilidade no ensino superior com vistas a um modelo que tem sido chamado de Universidade Sustentável (US) (Bizerril et al., 2018). Na visão de Disterheft et al. (2012), um campus sustentável deve considerar tanto os aspectos operacionais do ensino, da pesquisa e da gestão institucional referentes à redução do consumo de energia, de materiais, da emissão de gases e do lixo gerado, quanto os aspectos educacionais de ensinar sustentabilidade e proporcionar oportunidades para que a comunidade interna e externa possa aprender, refletir e desenvolver novas práticas e conceitos de estilo de vida que promovam o bem estar da atual e das futuras gerações.

Conforme Tauchen e Brandli (2006), o papel das IES no desenvolvimento sustentável destaca-se principalmente em duas frentes: a primeira evidencia a questão educacional como fundamental para que essas instituições contribuam para a formação de profissionais preocupados com as questões ambientais; e a segunda frente destaca a conduta de algumas IES na implantação de sistemas de gestão ambiental em seus campi, como modelos e exemplos práticos de gestão sustentável para a sociedade. Para estes autores, existem razões significativas para implantar um Sistema de Gestão Ambiental numa IES, entre elas o fato de que as faculdades e universidades podem ser comparadas a pequenos núcleos urbanos, envolvendo múltiplas atividades de ensino, pesquisa, extensão e processos, referentes ao funcionamento de bares, restaurantes, alojamentos estudantis, entre outras atividades. Complementarmente, um campus precisa de infraestrutura básica, de redes de abastecimento de água, energia e saneamento, coleta de águas pluviais e vias de acesso. Como consequência das atividades de operação de um campus, há a geração de resíduos sólidos e efluentes líquidos, bem como o consumo de recursos naturais, o que justifica a avaliação das diferentes ações ambientais desenvolvidas por estas instituições.

\section{Desenvolvimento de um modelo de avaliação de iniciativas ambientais presentes nas IES}

Lunardi et al. (2014a), ao avaliarem o grau de utilização de práticas ambientais na área de informática pelas organizações, verificaram que é possível mensurar a efetividade das iniciativas organizacionais voltadas à sustentabilidade ambiental através de cinco principais aspectos: (a) o nível de consciência socioambiental da organização; (b) o grau de orientação ambiental da organização; (c) o grau de expertise ambiental da organização nessa área; (d) o monitoramento das atividades operacionais; e (e) a efetividade de ações sustentáveis aplicadas à organização. San Martin (2018), utilizando o mesmo modelo, propôs a inclusão da orientação governamental como outro importante fator influenciador na avaliação da sustentabilidade, especialmente nas organizações públicas.

Adaptando este modelo para a realidade das IES e baseado na bibliografia revisada, principalmente sobre Gestão Ambiental e a sua aplicação em tais instituições, observou-se que em muitas IES a gestão ambiental está presente sob a forma de Políticas e Estratégias Organizacionais, pelo grau de Orientação Ambiental da organização (baseado em suas campanhas, recomendações, atividades voltadas para práticas mais sustentáveis), pela influência das Regulamentações Governamentais (relação da instituição com as leis ambientais que afetam suas atividades), pela presença de Estruturas Formais relacionadas à gestão ambiental na instituição (como coordenações, comitês, conselhos e sistemas ligados à gestão ambiental) e pela presença de iniciativas de Educação Ambiental em 
diferentes níveis da instituição (seja através de temas ambientais presentes nos currículos dos cursos, nas capacitações proporcionadas aos servidores e alunos, e ainda em cursos de extensão). Na visão de Careto e Vendeirinho (2003), as Universidades e outras Instituições de Ensino Superior devem colocar em prática aquilo que ensinam. Nesse sentido, ensinar conceitos e práticas de sustentabilidade que estimulem a responsabilidade ambiental dos alunos também deve fazer parte da gestão. Dessa forma, as Ações Ambientais desenvolvidas pelas organizações são o elemento prático que impulsiona a transformação da instituição em uma organização sustentável, seja realizando a correta coleta e descarte de lixo, economizando ou aproveitando melhor os seus recursos, apresentando construções sustentáveis, dentre outras.

Os gestores têm sido unânimes ao afirmarem que a gestão ambiental oportuniza um grande retorno para todos os tipos de organizações, seja na forma da eliminação de desperdícios, seja melhorando sua imagem, diminuindo os custos de atividade ou ainda construindo uma cultura baseada em valores ambientais (Almeida et al., 2000). Coelho e Alencastro (2009) defendem que as instituições que incorporam objetivos ambientais em seu gerenciamento acabam gastando menos com adequações legais, energia, água, papel, entre outros; sofrem menos desgaste com os passivos ambientais e, consequentemente, gastam menos com a logística reversa dos resíduos; têm sua imagem favorecida diante da sociedade e contam com maior simpatia por parte da mídia e perante as organizações e grupos ambientalistas, justificando porque muitas IES têm procurado desenvolver bons SGAs. A partir dos diferentes aspectos ambientais abordados pelas IES identificados na literatura, propôs-se um modelo conceitual.

\section{Metodologia}

O estudo caracteriza-se como uma pesquisa quantitativa de caráter exploratório, realizada em uma universidade federal do sul do Brasil, cujos respondentes $(\mathrm{n}=333$ ) eram discentes, docentes e técnicos administrativos da universidade. A pesquisa, realizada entre os meses de julho e agosto de 2019, envolveu uma etapa exploratória, na qual foi desenvolvido o instrumento de pesquisa, e outra quantitativa, englobando procedimentos de coleta, validação e análise de dados.

\section{Etapa exploratória}

O instrumento de coleta de dados foi desenvolvido a partir de uma adaptação do questionário elaborado por San Martin (2018), incluindo-se a este, novas questões abordando especificamente itens referentes às possíveis Estruturas Formais e práticas de Educação Ambiental presentes nas IES - variáveis propostas pelos autores desta pesquisa. Os itens referentes a essas duas variáveis foram retirados da literatura, sendo adaptados em forma de questão.

Como estratégia de investigação foi adotada a pesquisa survey. Este tipo de pesquisa se caracteriza pelo questionamento direto às pessoas, cujo comportamento se deseja conhecer. Mais especificamente, solicita-se um conjunto de informações a um grupo significativo de pessoas acerca do problema investigado para, posteriormente, obter conclusões referentes aos dados coletados, através do uso de técnicas e testes estatísticos (Gil, 2002). No presente estudo, foram utilizadas questões estruturadas e pré-definidas como forma de coleta dos dados, através da aplicação de um questionário composto por questões fechadas.

0 instrumento foi estruturado em dois blocos, sendo o primeiro responsável pela caracterização do respondente, contendo questões como: principal vínculo com a instituição, local em que desenvolve suas atividades, tempo de instituição, idade, escolaridade e gênero. No segundo bloco foram apresentadas 32 afirmações acerca de diferentes iniciativas e ações ambientais presentes, em maior ou menor escala, na 
universidade. Para avaliar cada uma dessas questões, foi utilizada uma escala tipo Likert (1932) de concordância com cinco pontos, sendo 1 para "discordo totalmente" e 5 para "concordo totalmente". Ao final, incluiu-se uma questão aberta proporcionando ao respondente espaço para realizar críticas, comentários ou sugestões acerca da pesquisa. Além disso, solicitou-se a cada respondente que caso tivesse interesse em receber os resultados da pesquisa, que disponibilizasse o seu e-mail.

Antes de iniciar a etapa de coleta dos dados, realizou-se um pré-teste com seis indivíduos (docentes, discentes e técnicos administrativos), dos quais metade atuava na Coordenadoria de Gestão Ambiental da Universidade, portanto, possuindo experiência e conhecimento na área, enquanto que os demais representavam o perfil da amostra. 0 propósito dessa etapa foi verificar potenciais fragilidades do instrumento ou dificuldades identificadas pelos respondentes no seu preenchimento. Foi solicitado a cada participante do pré-teste que relatasse qualquer ambiguidade, erro ou dúvida com relação às questões, à estrutura do instrumento ou qualquer dificuldade de interpretação. Ao final desse procedimento, não foi apontada qualquer necessidade de alteração por parte dos respondentes. As questões presentes no questionário, incluindo as questões eliminadas após os procedimentos de validação, podem ser visualizadas na Tabela 1.

Tabela 1. Questões do instrumento aplicado.

\begin{tabular}{|c|c|}
\hline \multirow{2}{*}{ Item } & Questão \\
\hline & A instituição... \\
\hline $\mathrm{q} 01^{*}$ & possui estratégias e políticas para a utilização de recursos naturais (ex. água,luz, papel) \\
\hline q02 & $\begin{array}{l}\text { faz campanhas de conscientização sobre o uso racional dos recursos naturais, junto à } \\
\text { comunidade universitária }\end{array}$ \\
\hline q03* & $\begin{array}{l}\text { possui bons programas de gestão que visam a sustentabilidade e o cuidado com o meio } \\
\text { ambiente }\end{array}$ \\
\hline $\mathrm{q} 04^{*}$ & possui estruturas que auxiliam na implementação de práticas ambientais \\
\hline $\mathrm{q} 05$ & promove eventos que abordam temas ambientais em suas programações \\
\hline q06 & $\begin{array}{l}\text { informa constantemente aos servidores e alunos sobre a forma correta de descartar } \\
\text { resíduos (lixo reciclável, orgânico, resíduos perigosos...) }\end{array}$ \\
\hline $\mathrm{q} 07^{*}$ & é incentivada pelo governo a praticar uma gestão mais sustentável e eficiente \\
\hline q08* & possui setores atuantes dedicados à área de gestão ambiental \\
\hline q09 & $\begin{array}{l}\text { oferece à comunidade universitária oficinas/seminários/cursos envolvendo o tema } \\
\text { ambiental }\end{array}$ \\
\hline $\mathrm{q} 10$ & possui estratégias e políticas ambientais bem definidas \\
\hline q11 & $\begin{array}{l}\text { faz recomendações aos servidores e alunos sobre como economizar água, energia e outros } \\
\text { recursos naturais }\end{array}$ \\
\hline q12 & $\begin{array}{l}\text { segue orientações e regulamentações governamentais para adquirir produtos e } \\
\text { equipamentos de forma sustentável }\end{array}$ \\
\hline q13 & $\begin{array}{l}\text { busca abordar temáticas associadas à sustentabilidade em seus cursos de capacitação, } \\
\text { graduação ou pós graduação }\end{array}$ \\
\hline q14 & $\begin{array}{l}\text { faz comunicação constante para apagar a luz ao sair, desligar equipamentos, não deixar ar } \\
\text { condicionado ligado, nem torneiras abertas }\end{array}$ \\
\hline $\mathrm{q} 15$ & incentiva a comunidade universitária a ser multiplicadora de ações de sustentabilidade \\
\hline $\mathrm{q} 16$ & segue corretamente as legislações ambientais \\
\hline $\mathrm{q} 17$ & tem em seu planejamento formal bons objetivos e metas relacionadas à gestão ambiental \\
\hline q18 & $\begin{array}{l}\text { incentiva o desenvolvimento de pesquisas e ações que busquem soluções para os } \\
\text { problemas ambientais }\end{array}$ \\
\hline q19 & possui critérios de cuidado com o meio ambiente bem definidos \\
\hline $\mathrm{q} 20$ & incentiva a diminuição do uso de recursos como papel, toner, copos plásticos \\
\hline
\end{tabular}


Tabela 1. Continuação.

\begin{tabular}{|c|l|}
\hline \multirow{2}{*}{ Item } & \multicolumn{1}{|c|}{ Questão } \\
\cline { 2 - 3 } & A instituição... \\
\hline q21 & define suas ações observando possíveis sanções ambientais \\
\hline q22 & possui programas e recursos destinados à gestão ambiental \\
\hline q23* & tem colaborado com a formação de profissionais preocupados com as questões ambientais \\
\hline Item & De modo geral, considero que a universidade... \\
\hline q24 & realiza a correta destinação de seus resíduos \\
\hline q25 & possui lixeiras suficientes para a separação do lixo \\
\hline q26 & $\begin{array}{l}\text { possui prédios com construções sustentáveis (reaproveitamento de água, iluminação } \\
\text { natural, preservação de áreas verdes) }\end{array}$ \\
\hline q27 & $\begin{array}{l}\text { adquire equipamentos levando em consideração sua eficiência energética (menor consumo } \\
\text { de energia, selo Procel) }\end{array}$ \\
\hline q28 & utiliza predominantemente a impressão frente e verso de seus documentos \\
\hline q29* & utiliza prioritariamente papel reciclado \\
\hline q30 & possui lâmpadas eficientes em seus prédios \\
\hline q31 & utiliza torneiras com fechamento automático (de pressão) \\
\hline q32 & $\begin{array}{l}\text { utiliza boas alternativas para diminuir o consumo de recursos naturais (combustível, papel, } \\
\text { energia) }\end{array}$ \\
\hline
\end{tabular}

Legenda: * Itens excluídos após os procedimentos de validação do instrumento.

\section{Etapa quantitativa}

A população do estudo é composta pelos alunos, professores e técnicos administrativos, os quais desempenham suas atividades no campus central da universidade, seja trabalhando ou estudando, há pelo menos um ano na instituição. Utilizando-se os dados da universidade e realizando uma apuração a partir dos critérios de inclusão acima mencionados, definiu-se a população do estudo em aproximadamente 9.600 potenciais respondentes. A amostra foi selecionada de forma probabilística e aleatória. Para isso, estabeleceu-se o tamanho mínimo de integrantes do estudo necessários para representar a população investigada, a partir do critério de seleção do tamanho amostral sugerido por Hill e Hill (2002), o que chegou a um total de 374 respondentes, considerando-se um nível de confiança de 95\%.

De posse do instrumento de coleta de dados previamente testado, procedeu-se a sua aplicação aos membros da comunidade universitária. Os dados foram coletados durante 40 dias, através do envio de um questionário eletrônico enviado diretamente ao email dos participantes. Ao final, 374 questionários retornaram, sendo 333 considerados válidos para análise (questionários mal preenchidos e com muitas questões em branco foram descartados). Os discentes representaram 48,6\% $(n=162)$, os técnicos administrativos $30,9 \%(n=103)$ e os docentes $20,4 \%(n=68)$. A maior representatividade dos alunos retrata a proporção desta categoria em relação às demais na população total do estudo (aproximadamente 86\%). Outras características da amostra estão apresentadas na Tabela 2. 
Tabela 2. Caracterização da amostra.

\begin{tabular}{|l|r|r|}
\hline Tempo na Instituição & $\mathbf{n}$ & $\mathbf{\%}$ \\
\hline 1 a 5 anos & 213 & 64,0 \\
\hline 5 a 10 anos & 60 & 18,0 \\
\hline 10 a 15 anos & 23 & 7,0 \\
\hline 15 a 20 anos & 7 & 2,0 \\
\hline 20 a 25 anos & 14 & 4,0 \\
\hline Mais de 25 anos & 16 & 5,0 \\
\hline Escolaridade & & \\
\hline Ensino Médio & 116 & 34,8 \\
\hline Graduação & 48 & 14,4 \\
\hline Pós-Graduação & 169 & 50,8 \\
\hline Gênero & & \\
\hline Feminino & 198 & 59,5 \\
\hline Masculino & 133 & 40,0 \\
\hline Outro & 2 & 0,5 \\
\hline
\end{tabular}

Posteriormente ao término da coleta de dados e purificação dos questionários, procedeu-se à validação do instrumento e à análise dos resultados, os quais são apresentados na próxima seção.

\section{Resultados}

Com o intuito de validar o instrumento proposto, foram realizados dois testes estatísticos: a) a análise fatorial exploratória (AFE), para verificar se os itens se agrupavam em seus respectivos constructos de origem; e b) o cálculo do coeficiente Alfa de Cronbach, o qual é utilizado para verificar a confiabilidade das escalas.

A AFE foi realizada a partir da inclusão de todas as 32 questões propostas no instrumento, com o intuito de verificar a consistência do modelo proposto, assim como se as questões se agrupariam conforme o esperado. A análise dos componentes se deu através da rotação dos fatores (usando o método Varimax). Segundo Hair Jr. et al. (2009), a matriz após a rotação dos fatores permite uma classificação mais precisa dos itens em cada um dos fatores latentes, ou seja, esta matriz indica, após realizar a rotação dos fatores, quais questões pertencem a cada fator.

A AFE sugeriu uma solução diferente do modelo proposto, agrupando as questões em quatro grupos (Tabela 3). Ao se analisar a distribuição dos itens do questionário nos fatores, bem como o sentido das questões, verificou-se que alguns dos itens referentes aos construtos Orientação Governamental, Estruturas Formais e Política Ambiental se agruparam, sugerindo a formação de um único fator. Considerando-se o conteúdo das questões destes construtos, pode-se perceber que os respondentes compreenderam os seus itens como se referindo a uma mesma temática, mais próxima da variável Política Ambiental. Já a Orientação Ambiental, a Educação Ambiental e as Ações Ambientais confirmaram as suas questões, conforme o seu agrupamento prévio, apresentando uma pequena variação na questão q15 (que migrou da variável Educação Ambiental para a Orientação Ambiental). Ao final dessa análise, sete itens foram excluídos do modelo por apresentarem cargas fatoriais baixas no seu respectivo fator ou elevadas em mais de um, restando 25 questões validadas. 
Tabela 3. Análise Fatorial Exploratória (Rotação Varimax).

\begin{tabular}{|c|c|c|c|c|}
\hline Indicadores & F1 & F2 & F3 & F4 \\
\hline \multicolumn{5}{|l|}{ Orientação ambiental $(a=0,89)$} \\
\hline $\begin{array}{l}\text { 14. Faz comunicação constante para apagar a luz ao sair, desligar } \\
\text { equipamentos, não deixar ar condicionado ligado, nem torneiras } \\
\text { abertas }\end{array}$ & 0,763 & 0,134 & 0,140 & 0,246 \\
\hline $\begin{array}{l}\text { 15. Incentiva a comunidade universitária a ser multiplicadora de } \\
\text { ações de sustentabilidade }\end{array}$ & 0,731 & 0,403 & 0,198 & 0,137 \\
\hline $\begin{array}{l}\text { 11. Faz recomendações aos servidores e alunos sobre como } \\
\text { economizar água, energia e recursos naturais }\end{array}$ & 0,706 & 0,333 & 0,262 & 0,187 \\
\hline $\begin{array}{l}\text { 2. Faz campanhas de conscientização sobre o uso racional dos } \\
\text { recursos naturais, junto à comunidade universitária }\end{array}$ & 0,692 & 0,305 & 0,238 & 0,095 \\
\hline $\begin{array}{l}\text { 6. Informa constantemente aos servidores e alunos sobre a forma } \\
\text { correta de descartar resíduos (lixo reciclável, orgânico, resíduos } \\
\text { perigosos...) }\end{array}$ & 0,657 & 0,179 & 0,255 & 0,262 \\
\hline $\begin{array}{l}\text { 20. Incentiva a diminuição do uso de recursos como papel, toner, } \\
\text { copos plásticos }\end{array}$ & 0,608 & 0,213 & 0,330 & 0,295 \\
\hline \multicolumn{5}{|l|}{ Educação ambiental $(a=0,89)$} \\
\hline $\begin{array}{l}\text { 9. Oferece à comunidade universitária oficinas/seminários/cursos } \\
\text { envolvendo o tema ambiental }\end{array}$ & 0,161 & 0,761 & 0,222 & 0,051 \\
\hline $\begin{array}{l}\text { 23. Tem colaborado com a formação de profissionais preocupados } \\
\text { com as questões ambientais }\end{array}$ & 0,168 & 0,685 & 0,220 & 0,226 \\
\hline $\begin{array}{l}\text { 5. Promove eventos que abordam temas ambientais em suas } \\
\text { programações }\end{array}$ & 0,170 & 0,673 & 0,307 & 0,012 \\
\hline $\begin{array}{l}\text { 13. Busca abordar temáticas associadas à sustentabilidade em seus } \\
\text { cursos de capacitação, graduação ou } 3\end{array}$ & 0,324 & 0,659 & 0,200 & 0,122 \\
\hline $\begin{array}{l}\text { 18. Incentiva o desenvolvimento de pesquisas e ações que busquem } \\
\text { soluções para os problemas ambientais }\end{array}$ & 0,281 & 0,657 & 0,146 & 0,197 \\
\hline 22. Possui programas e recursos destinados à gestão ambiental & 0,142 & 0,557 & 0,469 & 0,232 \\
\hline \multicolumn{5}{|l|}{ Política ambiental $(a=0,86)$} \\
\hline 16. Segue corretamente as legis & 0,193 & 0,132 & 0,787 & 0,186 \\
\hline 21. Define suas ações observando possíveis sanções ambientais & 0,197 & 0,300 & 0,680 & 0,164 \\
\hline $\begin{array}{l}\text { 17. Tem em seu planejamento formal bons objetivos e metas } \\
\text { relacionadas à gestão ambiental }\end{array}$ & 0,243 & 0,354 & 0,677 & 0,091 \\
\hline 19. Possui critérios de cuidado com o meio ambiente bem definidos & 0,410 & 0,317 & 0,646 & 0,171 \\
\hline 10. Possui estratégias e políticas ambientais bem definidas & 0,352 & 0,407 & 0,601 & 0,089 \\
\hline $\begin{array}{l}\text { 12. Segue orientações e regulamentações governamentais para } \\
\text { adquirir produtos e equipamentos de forma sustentável }\end{array}$ & 0,175 & 0,318 & 0,598 & 0,257 \\
\hline \multicolumn{5}{|l|}{ Ações ambientais $(\mathrm{a}=\mathbf{1}, \mathbf{8 1})$} \\
\hline 31. Utiliza torneiras com fechame & $-0,020$ & 0,239 & $-0,161$ & 0,704 \\
\hline 30. Possui lâmpadas eficientes em seus prédios & 0,094 & 0,034 & 0,244 & 0,654 \\
\hline $\begin{array}{l}\text { 27. Adquire equipamentos levando em consideração sua eficiência } \\
\text { energética (menor consumo de energia, selo Procel...) }\end{array}$ & 0,184 & 0,231 & 0,292 & 0,651 \\
\hline $\begin{array}{l}\text { 32. Utiliza boas alternativas para diminuir o consumo de recursos } \\
\text { naturais (combustível, papel, energia) }\end{array}$ & 0,505 & 0,212 & 0,183 & 0,598 \\
\hline $\begin{array}{l}\text { 26. Possui prédios com construções sustentáveis (reaproveitamento } \\
\text { de água, iluminação natural, preservação de áreas verdes) }\end{array}$ & 0,271 & 0,124 & 0,225 & 0,593 \\
\hline $\begin{array}{l}\text { 28. Utiliza predominantemente a impressão frente e verso de seus } \\
\text { documentos }\end{array}$ & 0,417 & 0,046 & 0,073 & 0,583 \\
\hline 25. Possui lixeiras suficientes para a separação do lixo & 0,337 & $-0,077$ & 0,290 & 0,479 \\
\hline Initial Eingen value & 10,8 & 2,04 & 1,40 & 1,20 \\
\hline \% Variância Explicada - rotada (61,2\%) & 43,1 & 8,15 & 5,19 & 4,79 \\
\hline \multicolumn{5}{|l|}{ Alfa de Cronbach (instrumento) - 0,94 } \\
\hline KMO & & & & \\
\hline
\end{tabular}


As quatro dimensões do instrumento explicam $61,2 \%$ da variação das questões originais, o que representa um adequado grau de sintetização dos dados. 0 teste KMO de medida de adequação da amostra apresentou valor 0,94 , também demonstrando um elevado grau de ajuste dos dados para a aplicação da AFE, sendo este ratificado pelo teste de esfericidade de Bartlett, que apresentou nível de significância 0,000. Ao final da nova formação, verificou-se a confiabilidade das escalas pelo alfa de Cronbach, os quais apresentaram valores entre 0,81 e 0,89, considerados satisfatórios para estudos dessa natureza.

\section{Aplicação do modelo: análise descritiva}

Como forma de verificar a funcionalidade do modelo desenvolvido, o mesmo foi primeiramente analisado de forma descritiva. Essa análise permite identificar a percepção da comunidade universitária a respeito das iniciativas desenvolvidas pela instituição voltadas à gestão ambiental (Tabela 4).

Tabela 4. Análise descritiva.

\begin{tabular}{|c|c|c|c|}
\hline Variáveis & Média & $\begin{array}{l}\text { Desvio- } \\
\text { Padrão }\end{array}$ & $\mathbf{n}$ \\
\hline Educação ambiental & 3,54 & 1,09 & 328 \\
\hline $\begin{array}{l}\text { 23. Tem colaborado com a formação de profissionais preocupados } \\
\text { com as questões ambientais }\end{array}$ & 3,74 & 1,04 & 328 \\
\hline $\begin{array}{l}\text { 5. Promove eventos que abordam temas ambientais em suas } \\
\text { programações }\end{array}$ & 3,70 & 1,05 & 328 \\
\hline $\begin{array}{l}\text { 18. Incentiva o desenvolvimento de pesquisas e ações que busquem } \\
\text { soluções para os problemas ambientais }\end{array}$ & 3,58 & 1,02 & 328 \\
\hline 22. Possui programas e recursos destinados à gestão ambiental & 3,57 & 1,07 & 328 \\
\hline $\begin{array}{l}\text { 9. Oferece à comunidade universitária oficinas/seminários/cursos } \\
\text { envolvendo o tema ambiental }\end{array}$ & 3,41 & 1,17 & 328 \\
\hline $\begin{array}{l}\text { 13. Busca abordar temáticas associadas à sustentabilidade em seus } \\
\text { cursos de capacitação, graduação ou extensão }\end{array}$ & 3,26 & 1,18 & 328 \\
\hline Política ambiental & 3,27 & 1,09 & 325 \\
\hline 16. Segue corretamente as legislações ambientais & 3,45 & 1,08 & 325 \\
\hline $\begin{array}{l}\text { 17. Tem em seu planejamento formal bons objetivos e metas } \\
\text { relacionadas à gestão ambiental }\end{array}$ & 3,40 & 1,07 & 325 \\
\hline 21. Define suas ações observando possíveis sanções ambientais & 3,26 & 1,09 & 325 \\
\hline 19. Possui critérios de cuidado com o meio ambiente bem definidos & 3,24 & 1,10 & 325 \\
\hline 10. Possui estratégias e políticas ambientais bem definidas & 3,22 & 1,16 & 325 \\
\hline $\begin{array}{l}\text { 12. Segue orientações e regulamentações governamentais para } \\
\text { adquirir produtos e equipamentos de forma sustentável }\end{array}$ & 3,06 & 1,08 & 325 \\
\hline Ações ambientais & 2,88 & 1,22 & 326 \\
\hline 31. Utiliza torneiras com fechamento automático (de pressão) & 3,40 & 1,39 & 326 \\
\hline 25. Possui lixeiras suficientes para a separação do lixo & 3,12 & 1,39 & 326 \\
\hline 30. Possui lâmpadas eficientes em seus prédios & 2,95 & 1,21 & 326 \\
\hline $\begin{array}{l}\text { 27. Adquire equipamentos levando em consideração sua eficiência } \\
\text { energética (menor consumo de energia, selo Procel...) }\end{array}$ & 2,84 & 1,05 & 326 \\
\hline $\begin{array}{l}\text { 32. Utiliza boas alternativas para diminuir o consumo de recursos } \\
\text { naturais (combustível, papel, energia) }\end{array}$ & 2,62 & 1,06 & 326 \\
\hline $\begin{array}{l}\text { 28. Utiliza predominantemente a impressão frente e verso de seus } \\
\text { documentos }\end{array}$ & 2,60 & 1,26 & 326 \\
\hline $\begin{array}{l}\text { 26. Possui prédios com construções sustentáveis (reaproveitamento } \\
\text { de água, iluminação natural, preservação de áreas verdes) }\end{array}$ & 2,59 & 1,18 & 326 \\
\hline
\end{tabular}


Tabela 4. Análise descritiva.

\begin{tabular}{|l|c|c|c|}
\hline Variáveis & Média & $\begin{array}{c}\text { Desvio- } \\
\text { Padrão }\end{array}$ & $\mathbf{n}$ \\
\hline Orientação ambiental & $\mathbf{2 , 7 4}$ & $\mathbf{1 , 2 6}$ & $\mathbf{3 2 9}$ \\
\hline $\begin{array}{l}\text { 14. Faz comunicação constante para apagar a luz ao sair, desligar } \\
\text { equipamentos, não deixar ar condicionado ligado, nem torneiras } \\
\text { abertas }\end{array}$ & 2,88 & 1,37 & 329 \\
\hline $\begin{array}{l}\text { 15. Incentiva a comunidade universitária a ser multiplicadora de } \\
\text { ações de sustentabilidade }\end{array}$ & 2,84 & 1,24 & 329 \\
\hline $\begin{array}{l}\text { 20. Incentiva a diminuição do uso de recursos como papel, toner, } \\
\text { copos plásticos }\end{array}$ & 2,81 & 1,29 & 329 \\
\hline $\begin{array}{l}\text { 2. Faz campanhas de conscientização sobre o uso racional dos } \\
\text { recursos naturais, junto à comunidade universitária }\end{array}$ & 2,68 & 1,22 & 329 \\
\hline $\begin{array}{l}\text { 6. Informa constantemente aos servidores e alunos sobre a forma } \\
\text { correta de descartar resíduos (lixo reciclável, orgânico, resíduos } \\
\text { perigosos...) }\end{array}$ & 2,68 & 1,29 & 329 \\
\hline $\begin{array}{l}\text { 11. Faz recomendações aos servidores e alunos sobre como } \\
\text { economizar água, energia e recursos naturais }\end{array}$ & 2,54 & 1,18 & 329 \\
\hline
\end{tabular}

Neste sentido, identificou-se que as iniciativas relacionadas à Educação Ambiental realizadas pela IES foram os aspectos melhor avaliados pelos respondentes, apresentando uma média igual a 3,54. Dentre essas iniciativas, a formação de profissionais preocupados com as questões ambientais $(3,74)$ e a promoção de eventos abordando temas ambientais $(3,70)$ foram as que mais se destacaram. Por outro lado, a oferta de oficinas, seminários e cursos sobre meio ambiente $(3,41)$ e a inserção de temas ligados à sustentabilidade nas capacitações e cursos $(3,26)$ foram avaliados como pontos que necessitam de maior atenção por parte da instituição.

Conforme Thomaz (2006), a responsabilidade das IES quanto à educação ambiental vai além de se criar cursos e de tornar os currículos mais "verdes". A ambientalização da universidade supera a concepção estrita de currículo e inclui a dimensão ambiental no fazer acadêmico/universitário. Complementarmente, Jacobi (2003) relata que a necessidade de uma crescente internalização da problemática ambiental demanda grandes esforços para fortalecer visões integradoras que estimulem reflexões sobre a diversidade e a construção de sentidos em torno das relações existentes entre os indivíduos e a natureza, bem como os riscos ambientais (globais e locais) e a relação entre ambiente e desenvolvimento. A educação ambiental, nesse contexto, oportuniza espaços para repensar diferentes práticas sociais, assim como o papel dos professores como mediadores e transmissores do conhecimento necessário para que os estudantes adquiram uma base adequada para compreender o meio ambiente, em sua esfera global e local, bem como pensar nos problemas ambientais e suas possíveis soluções, e refletir sobre a importância da responsabilidade de cada um na construção de uma sociedade mais justa e ambientalmente sustentável.

Em seguida, destacaram-se, também, as iniciativas relacionadas às Políticas Ambientais da instituição $(3,27)$, com uma avaliação ainda superior ao ponto médio da escala. Como aspectos melhor avaliados estão o compromisso da organização em seguir as legislações ambientais $(3,45)$ e a presença de objetivos e metas relacionados à gestão ambiental em seu planejamento institucional $(3,40)$. Tinoco e Kraemer $(2004)$ destacam que a gestão ambiental inclui a presença de estruturas organizacionais, atividades de planejamento, práticas, processos e recursos para desenvolver, implementar, analisar e manter a política ambiental. 
Em contraponto, a comunidade percebeu apenas de forma razoável que a IES adquire equipamentos e produtos mais sustentáveis $(3,06)$. Cavenaghi et al. (2018) relatam que a busca pela sustentabilidade nas organizações é um processo contínuo e que deve ser construído de forma conjunta para que os resultados sejam mantidos e aprimorados a longo prazo. A Agenda Ambiental da Administração Pública (A3P), por exemplo, orienta a inserção de critérios sociais, ambientais e econômicos nas aquisições realizadas pelos órgãos públicos, de modo a gerar benefícios econômicos e sociais (Brasil, 2019). De outra maneira, torna-se apenas um discurso vindo dos altos escalões da organização se a maioria das instituições não as cumpre, fazendo com que as ações sustentáveis fiquem em um plano superficial.

Com relação à percepção da comunidade universitária quanto às Ações Ambientais desenvolvidas pela Universidade, esta não apresentou uma boa avaliação, apresentando média igual a 2,88. A presença de torneiras com fechamento automático $(3,40)$ e a distribuição de lixeiras para separação do lixo $(3,11)$ foram as únicas ações ambientais que tiveram sua avaliação superior ao ponto médio da escala utilizada, sugerindo que este grupo de iniciativas precisa ser intensificado na instituição. Além disso, aspectos como a busca por alternativas para diminuição do consumo de recursos naturais $(2,62)$, o elevado volume de impressões $(2,60)$ e a presença de construções sustentáveis $(2,59)$ apresentaram avaliações negativas. Lunardi et al. (2014b) apontam que ao se adotarem ações práticas associadas à impressão, são percebidos benefícios como: redução de custos, economia de espaço e economia de papel, sendo estes proporcionados especialmente pela digitalização dos documentos, pelo monitoramento de impressões, pelas impressões frente-e-verso e por uma maior conscientização quanto à necessidade de gerar impressões. Quanto às construções sustentáveis, a adoção de medidas durante todas as etapas da obra visando a sustentabilidade da edificação, pode diminuir os impactos negativos sobre o meio ambiente e promover a economia de recursos naturais, repercutindo na melhoria da qualidade de vida dos seus ocupantes (Brasil, 2019).

Por fim, verificou-se que o aspecto pior avaliado pela comunidade universitária diz respeito às iniciativas de Orientação Ambiental $(2,74)$, sugerindo que a instituição não é percebida pela comunidade universitária como pró-ativa em diversos aspectos associados à temática ambiental. Ações como a presença de campanhas de conscientização $(2,67)$, informar sobre a forma correta de destinação de resíduos $(2,67)$ e ainda recomendar aos servidores e alunos como economizar água, energia e outros recursos $(2,54)$, não foram avaliadas pela comunidade universitária como satisfatórias. Segundo Lunardi et al. (2014a), a orientação ambiental da organização avalia em que grau a organização está comprometida com a sustentabilidade na sua instituição, adotando práticas e rotinas organizacionais que incentivem os indivíduos a desenvolver comportamentos que sigam as políticas de responsabilidade ambiental que a organização apoia (Jenkin et al., 2011).

Conforme San Martin (2018), há necessidade de as pessoas compreenderem como as suas atividades podem causar problemas ambientais e como as organizações podem se comprometer em mudar essa condição. Maçaneiro et al. (2015) complementam enfatizando que a orientação ambiental, estando desenvolvida internamente na instituição, incita a execução de ações que demonstram uma latente consideração com as questões ecológicas, ou seja, com a racionalização de energia, de insumos (papel, equipamentos) e etc.

\section{Aplicação do modelo: análise de regressão}

Com o intuito de identificar os principais fatores que influenciam significativamente a implementação das práticas ambientais adotadas pela IES, pode-se utilizar o modelo proposto a partir de uma análise de regressão múltipla. Neste caso, são definidas como variáveis independentes os construtos Educação Ambiental, Orientação Ambiental e Política Ambiental, e como variável dependente as Ações Ambientais. A 
análise de regressão permite medir, de forma indireta, o grau de influência das variáveis independentes sobre a efetividade das ações ambientais, permitindo visualizar, dessa forma, os fatores que - quando melhores ou piorados - influenciam significativamente a efetividade da implementação das práticas ambientais adotadas pela Universidade.

0 modelo apresentou um moderado grau de explicação da variável dependente $\left(\mathrm{R}^{2}=0,42 ; \mathrm{p}<0,000\right)$, possibilitando visualizar quais fatores interferem positivamente ou negativamente na efetividade das ações ambientais presentes na IES. Pôde-se perceber que os aspectos referentes à Orientação Ambiental $(\mathrm{r}=0,46 ; \mathrm{p}<0,000)$ e à Política Ambiental ( $r=0,19 ; p<0,01)$ apresentaram significância estatística com a variável dependente do modelo, sendo, portanto, os principais preditores do sucesso da implementação das ações ambientais na instituição. Nesse sentido, percebe-se que quanto maior for a Orientação Ambiental da instituição, seja através da presença de campanhas de conscientização, incentivos e recomendações sobre como diminuir o uso de recursos naturais, maior será a efetividade das suas Ações Ambientais, influenciando servidores e alunos quanto à correta destinação dos resíduos, à maior aquisição de equipamentos eficientes e ambientalmente corretos, à distribuição no campus de lixeiras para separação do lixo, busca de alternativas para economizar recursos e etc. Para Jenkin et al. (2011), as iniciativas ambientais influenciam positivamente as atitudes ambientais, cognições e comportamentos, de forma que quanto mais a organização fomenta e pratica ações sustentáveis, mais ela fica disposta e, consequentemente, insere novas ações sustentáveis. Ou seja, quanto mais pró-ativa a organização for em relação às iniciativas, incentivos e recomendações, maior será a aderência a práticas ambientais, resultando em uma orientação ambiental global mais positiva.

Da mesma forma, a presença de uma Política Ambiental que possua critérios de cuidados com o meio ambiente bem definidos, objetivos e metas relacionadas à gestão ambiental, e que siga às legislações ambientais se refletirá na implementação de ações ambientais mais efetivas. Van Weenen (2000) cita que há muitas formas das universidades promoverem a sustentabilidade, sejam elas nas ações de planejamento, gestão, desenvolvimento, operações, entre outros. Além disso, Oliveira Filho (2002) reforça que a proteção ao meio ambiente no entorno da organização, a identificação do cumprimento às leis e políticas ambientais e o aumento da consciência ambiental de todos os indivíduos da instituição melhora a imagem e traz diversos benefícios à organização. Por outro lado, quanto menos desenvolvidas forem a Política Ambiental e a Orientação Ambiental da instituição, menor será a efetividade das ações ambientais implementadas.

Já a educação ambiental, embora tenha sido o fator melhor avaliado pela comunidade universitária, esta não apresentou significância estatística com a efetividade das ações ambientais. Nesse sentido, Brandalise et al. (2009) sugerem que a educação ambiental deve estar comprometida com uma abordagem que interrelacione diferentes aspectos, sejam eles sociais, ecológicos, econômicos, políticos, culturais, científicos, tecnológicos e éticos. Nesse sentido, é difícil e complexo compreender com clareza os limites e as possibilidades da educação ambiental como um fator que motive a adoção de ações ambientais. Desse modo, os autores recomendam o desenvolvimento de projetos simples e objetivos, ajustados à vivência do cotidiano casa/escola/comunidade por meio da interdisciplinaridade, o que poderá repercutir numa melhor percepção da comunidade acadêmica quanto a sua influência nas ações ambientais adotadas pela organização.

\section{Considerações finais}

O presente artigo busca estimular a reflexão na comunidade acadêmica e de profissionais que atuam em diferentes instituições de ensino superior sobre as ações ambientais desenvolvidas nessas organizações. 0 estudo contribui num melhor entendimento sobre como são percebidas pela comunidade universitária as ações 
ambientais desenvolvidas pelas IES e o que interfere significativamente na efetividade dessas ações.

0 modelo proposto apresenta quatro fatores que representam diferentes iniciativas ambientais a serem desenvolvidas pelas universidades, sendo elas: a Educação Ambiental, a Orientação Ambiental, a Política Ambiental e as Ações Ambientais. Após a aplicação do instrumento junto a uma amostra de 333 indivíduos de uma Universidade pública brasileira, realizou-se a sua validação, que a partir de diferentes testes estatísticos sugeriu a eliminação de algumas questões, que não se mostraram consistentes com os construtos previamente propostos, bem como o agrupamento de alguns fatores.

0 modelo validado permite analisar a percepção da comunidade universitária quanto às iniciativas ambientais realizadas pela IES, além de identificar os fatores que influenciam significativamente a implementação das Ações Ambientais na universidade. Permite, ainda, comparar as percepções de diferentes grupos de respondentes, como alunos, professores e técnicos, setores de atuação e etc.

Com relação à aplicação do modelo na Universidade analisada, as iniciativas de Educação Ambiental e de Políticas Ambientais definidas pela Universidade apresentaram avaliações positivas da comunidade, destacando-se a percepção dos respondentes quanto à formação de profissionais preocupados com as questões ambientais, a promoção de eventos e pesquisas realizadas pela instituição abordando temas ambientais, o atendimento às legislações ambientais e a presença de objetivos e metas relacionadas à gestão ambiental presentes no planejamento da instituição como importantes iniciativas e bem desenvolvidas pela IES. Por outro lado, a Orientação Ambiental - marcada pelas campanhas, recomendações e atividades voltadas para práticas mais sustentáveis - não foi bem avaliada pelos respondentes, principalmente quanto à presença de campanhas de conscientização junto à comunidade universitária e recomendações sobre o uso racional de recursos da e na instituição.

Quanto aos principais fatores que influenciam significativamente a implementação das ações ambientais na instituição, verificou-se que os aspectos referentes à Orientação Ambiental e à Política Ambiental apresentam-se como os principais preditores do sucesso da implementação das ações ambientais, sugerindo que quanto melhor desenvolvidas forem essas iniciativas, mais efetiva será a implementação das diferentes ações ambientais adotadas pela instituição.

O estudo buscou ampliar a discussão sobre a adoção e a efetividade de diferentes iniciativas ambientais desenvolvidas pelas instituições de ensino superior. Nesse sentido, tem-se como contribuições da pesquisa a proposição de um modelo e de um instrumento que podem auxiliar os gestores na avaliação das práticas ambientais adotadas pelas suas instituições, servindo como uma ferramenta de apoio ao planejamento e à tomada de decisões envolvendo a temática gestão ambiental. Complementarmente, os resultados obtidos podem auxiliar outras instituições, sejam elas públicas ou privadas, através do uso de dados empíricos de modo que possam (re)pensar suas ações a partir do que já vem sendo realizado, podendo utilizar os itens presentes no instrumento como subsídios para a elaboração de estratégias associadas à responsabilidade socioambiental e desenvolvimento sustentável das organizações. Como pesquisas futuras, propõe-se estender o escopo da pesquisa para outras IES, de modo a analisar possíveis semelhanças e particularidades; aplicar o instrumento conjuntamente em IES públicas e privadas para analisar se o comportamento nestes dois tipos de instituições se assemelha; avaliar a possibilidade de testar o modelo proposto em outros tipos de organizações, além das instituições de ensino superior; e, por fim, considerando a finalidade da instituição pesquisada (ensino) e também o destaque da variável Educação Ambiental, sendo esta percebida de forma mais positiva pelos respondentes da pesquisa, novos estudos poderiam ser realizados considerando esta variável e sua relação com a efetividade de outras iniciativas e ações ambientais desenvolvidas pelas universidades. 
Como limitações da pesquisa, destaca-se que a coleta de dados restringiu-se a apenas uma IES, e que esta considerou somente o campus central da Universidade para análise, não considerando os demais campi avançados (menores e localizados em outros municípios), nem os trabalhadores terceirizados, o que pode influenciar os resultados da pesquisa como um todo, despertando cuidados quanto ao seu poder de generalização.

\section{Conflito de interesses}

Os autores declaram não haver conflito de interesses.

\section{Referências}

Alves, A. Responsabilidade ambiental: os benefícios de um Sistema de Gestão Ambiental (SGA) em instituições de ensino superior (IES). Revista da Universidade Ibirapuera, n. 13, p. 24-33, 2017.

Almeida, C.; Oliveira, D.; Perlin, H.; Didonet, S.; Ramaswami, R. Gestão ambiental responsabilidade com o futuro. Anais do XXVIII COBENGE, Ouro Preto/MG, 2000. Disponível em: <http://www.abenge.org.br/cobenge/arquivos/19/artigos/195.PDF>. Acesso em: 18 abr. 2020.

Almeida, T.; Sellitto, M. Avaliação de desempenho ambiental de uma instituição pública de ensino técnico e superior. Produção, v. 23, p.625-636, 2013. https://doi.org/10.1590/ S0103-65132012005000090

Barbieri, J. C. Gestão ambiental empresarial: conceitos, modelos e instrumentos. 4. ed. São Paulo: Saraiva, 2016.

Bizerril, M.; Rosa, M.; Carvalho, T.; Pedrosa, J. Construindo uma universidade sustentável: uma discussão baseada no caso de uma universidade portuguesa. Revista da Avaliação da Educação Superior, v. 23, n. 2, p. 424-447, 2018.

Brandalise, L. T.; Bertolini, G. R. F.; Rojo, C. A.; Lezana, A. G. R.; Possamai, O. A percepção e o comportamento ambiental dos universitários em relação ao grau de educação ambiental. Gestão \& Produção, v. 16, n. 2, p. 273-285, 2009. https://doi.org/10.1590/S0104530X2009000200010

Brasil. Ministério do Meio Ambiente. Agenda Ambiental da Administração Pública. 2019. Disponível em: <http://www.mma.gov.br/responsabilidade-socioambiental/a3p>. Acesso em: 05 fev. 2019.

Campos, L. M. S. Environmental management systems (EMS) for small companies: A study in Southern Brazil. Journal of Cleaner Production, v. 32, p. 141-148, 2012. https://doi.org/10.1016/j.jclepro.2012.03.029

Campos, L. M. S.; Heizen, D. A. M.; Verdinelli, M. A.; Miguel, P. A. C. Environmental performance indicators: A study on ISO 14001 certified companies. Journal of Cleaner Production, v. 99, p. 286-296, 2015. https://doi.org/10.1016/j.jclepro.2015.03.019

Careto, H.; Vendeirinho, R. Sistema de gestão ambiental em universidades: caso do Instituto Superior Técnico de Portugal. Lisboa: Instituto Superior Técnico de Portugal, 2003. (Tese de Licenciatura em Engenharia do Ambiente).

Cavenaghi, L.; Dias, L.; Marchiori, M. A interação entre os sujeitos (comunicação) e o processo de construção da sustentabilidade nas organizações. Gestão \& Sociedade, v. 12, n. 32, p. 2232-2256, 2018. https://doi.org/10.21171/ges.v12i32.2189 
Coelho, B.; Alencastro, M. O papel das pequenas e médias empresas brasileiras no desenvolvimento sustentável. Revista das Faculdades Santa Cruz, v. 7, n. 1, p. 87-93, 2009.

Disterheft, A.; Caeiro, S.; Ramos, M.; Azeiteiro, U. Environmental Management Systems (EMS) implementation processes and practices in European higher education institutions: Top-down versus participatory approaches. Journal of Cleaner Production, v. 31, p. 80-90, 2012. https://doi.org/10.1016/j.jclepro.2012.02.034

Druzzian, E. T. V.; Santos, R. C. Sistema de Gerenciamento Ambiental (SGA): buscando uma resposta para os resíduos de laboratórios das instituições de ensino médio e profissionalizante. Revista Liberato, v. 7, n. 7, p. 40-44, 2006.

Gazzoni, F.; Scherer, F. F.; Hahn, I. S.; Carpes, A. M.; Santos, M. B. O papel das IES no desenvolvimento sustentável: estudo de caso da Universidade Federal de Santa Maria. Gestão Universitária na América Latina - GUAL, v. 11, n. 1, p. 48-70, 2018. https://doi.org/10.5007/1983-4535.2018v11n1p48

Gil, A. Como elaborar projetos de pesquisa. 4. ed. São Paulo: Atlas, 2002.

Hair Jr., J.; Anderson, R.; Tatham, R.; Black, W. Análise multivariada de dados. 6. ed. Porto Alegre: Bookman, 2009.

Hill, M. M.; Hill, A. Investigação por questionário. Lisboa: Sílabo, 2002.

Jacobi, P. Educação ambiental, cidadania e sustentabilidade. Cadernos de Pesquisa, n. 118, p. 189-206, 2003. https://doi.org/10.1590/S0100-15742003000100008

Jenkin, T.; Webster, J.; McShane, L. An agenda for 'green' information technology systems

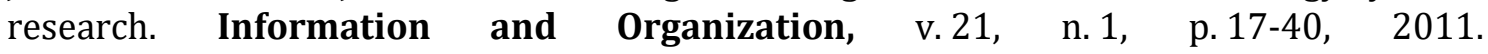
https://doi.org/10.1016/j.infoandorg.2010.09.003

Likert, R. A technique for the measurement of attitudes. Archives of Psychology, v. 22, n. 140, p. 5-55, 1932. Disponível em: <https://legacy.voteview.com/pdf/Likert_1932.pdf>. Acesso em: 18 abr. 2020.

Lunardi, G. L.; Alves, A. P.; Salles, A. C. Desenvolvimento de uma escala para avaliar o grau de utilização da tecnologia da informação verde pelas organizações. Revista de Administração, v. 49, n. 3, p. 591-605, 2014a. https://doi.org/10.5700/rausp1170

Lunardi, G. L.; Simões, R.; Frio, R. TI Verde: uma análise dos principais benefícios e práticas utilizadas pelas organizações. REAd. Revista Eletrônica de Administração, v. 20, n. 1, p. 1-30, 2014b. https://doi.org/10.1590/S1413-23112014000100001

Maçaneiro, M.; Sieglinde, K.; Kuhl, M.; Cunha, J. A regulamentação ambiental conduzindo estratégias ecoinovativas na indústria de papel e celulose. RAC - Revista de Administração Contemporânea, v. 19, n. 1, p.65-83, 2015. https://doi.org/10.1590/ 1982-7849rac20151779

Motta, E. M. T.; Scheneider, V. E.; Gimenez, J. R.; Kairisto-Mertanen, L. Boas práticas em gestão ambiental de Instituições de Ensino Superior: o caso da Universidade de Turku de Ciências Aplicadas. Scientia Cum Industria, v. 5, n. 1, p. 10-17, 2017. https://doi.org/ 10.18226/23185279.v5iss3p10

Nolasco, F.; Tavares, G.; Bendassolli, J. Establishment of laboratory waste management programs in universities: Critical review and recommendations. Engenharia Sanitária e

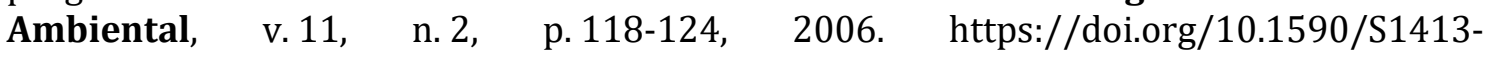
41522006000200004 
Oliveira Filho, M. A auditoria ambiental como ferramenta de apoio para o desempenho empresarial e a preservação do meio ambiente: uma abordagem contábil e gerencial em indústrias químicas. São Paulo: Faculdade de Economia, Administração e Contabilidade, Universidade de São Paulo, 2002. (Dissertação de mestrado).

Paradiso, R.; Monteiro, M.; Pinto, R. Gestão ambiental como fator de inovação em arranjos produtivos locais. Informe Econômico, v. 16, n. 31, p. 24-31, 2014.

Rodrigues, C.; Oliveira, I.; Pilatti, L. Abordagem dos resíduos sólidos de serviços de saúde na formação acadêmica em cursos da área da saúde. Anais do Congresso Internacional de Administração, Gestão Estratégica para o Desenvolvimento Sustentável, Ponta Grossa, 2007. Disponível em: <http://https://admpg.com.br/2019/anaisadm/2007/>. Acesso em: 18 abr. 2020.

San Martin, A. Adoção da TI Verde em organizações públicas federais do RS e seu impacto na sustentabilidade ambiental. Rio Grande: Universidade Federal do Rio Grande, 2018. (Dissertação de mestrado).

Silva, C.; Lima, D.; Farias, I.; Oliveira, D. Produção científica sobre gestão ambiental no Brasil: um estudo bibliométrico e de redes de coautoria. Revista Gestão \& Sustentabilidade Ambiental, v. 7, n. 2, p.426-451, 2018. https://doi.org/10.19177/ rgsa.v7e22018426-451

Tauchen, J.; Brandli, L. Gestão ambiental em instituições de ensino superior: modelo para implantação em campus universitário. Revista Gestão \& Produção, v. 13, n. 3, p. 503-515, 2006. https://doi.org/10.1590/S0104-530X2006000300012

Tinoco, J.; Kraemer, M. Contabilidade e gestão ambiental. São Paulo: Atlas, 2004.

Thomaz, C. Educação ambiental na formação inicial de professores. Campinas: Pontifícia Universidade Católica de Campinas, 2006. (Dissertação de mestrado).

Van Weenen, H. Towards a vision of a sustainable university. International Journal of Sustainability in Higher Education, v. 1, n. 1, p. 20-34, 2000. https://doi.org/10.1108/ 1467630010307075 